\title{
História e Antropologia: Relações Teórico-Metodológicas, Debates sobre os Objetos e os Usos das Fontes de Pesquisa
}

\author{
Irineia M. Franco dos Santos
}

Universidade Federal de Alagoas

\begin{abstract}
Resumo: O objetivo deste artigo é apresentar as principais relações teórico-metodológicas entre as áreas de História e Antropologia e seus debates no uso das fontes de pesquisa e escolha dos objetos. Sabe-se que as temáticas enfocadas pela História a partir da década de 1970 privilegiaram objetos de pesquisa até então pouco trabalhados na historiografia o que levou a uma busca por referências de análise das ciências sociais. Assim, os estudos históricos dos grupos culturais e suas temáticas (religião, símbolos, arte, educação, relações comunitárias e de poder etc) passaram a usar métodos de coleta de dados e análise com influências antropológicas. Quer-se aqui, refletir o quanto esses usos são bem entendidos pelos pesquisadores e como as duas áreas se vêem na produção do conhecimento específico antropológico e histórico. O caráter interdisciplinar (multidisciplinar) das ciências sociais e humanas deve ser discutido com o intuito de aprimorar as suas relações e esclarecer suas diferenças levando em conta as perspectivas políticas por trás das escolhas teóricas.
\end{abstract}

Palavras-chave: História e Antropologia, uso das fontes, problemas teórico-metodológicos

Abstract: The objective of this article is to present the main relations theoretic-methodological between the areas History and Anthropology and its debates in the use of the research sources and choice of objects. One knows that the thematic ones focused for History from the decade of 1970 had privileged objects of research until then little worked in the historiography what it led to a search for references of analysis of social sciences. Thus, the historical studies of thematic the cultural groups and its (religion, symbols, art, education, communitarian relations etc) had started to use methods of collection of data and analysis with anthropological influences. It is wanted here, to reflect how much these uses well are understood by the researchers and as the two areas if they see in the production of the anthropologic and historical specific knowledge. The character to interdisciplinary (to multidiscipline) of social sciences and human beings must be argued with intention to improve its relations and to clarify its differences leading in account the perspectives politics for backwards of the theoretical choices.

Key-words: History and Anthropology; use of the sources; theoretic-methodological problems

Os Negros não se sentem frustrados de sua História porque eles jamais tiveram História, e nem desejaram ter uma. Como os Gauleses ou os Germanos de antes da conquista romana ou que numerosos povos asiáticos ou oceânicos. Se eles desejassem hoje criar uma, seria o sinal de que eles queriam entrar no jogo do Mundo, que é, em grande parte, o jogo do Ocidente. $(\mathrm{H}$. Brunschwig. Histoire Passée et Frustration en Afrique Noire) ${ }^{1}$

Recusamos a teoria que nega a possibilidade de escrever a História da África Negra, deixando a este continente o direito apenas de uma etnohistória. Somos por uma história de múltiplas fontes e polivalente que

\footnotetext{
* Este texto foi apresentado como palestra durante o I Encontro de História: História de Alagoas, Historiografia e Documentação no Curso de História da Universidade Federal de Alagoas na mesa Abordagens Teóricas e Metodológicas da História, 24 de novembro de 2009, às 19hs.

** Professora Assistente do curso de História da Universidade Federal de Alagoas (UFAL), Doutoranda em História Social pela Universidade de São Paulo (USP).

${ }^{1}$ Annales, set.-out., 1962 in Dirceu LINDOSO. Lições de Etnologia Geral: introdução aos seus estudos e princípios, p. 107.
} 
tome em conta absolutamente todos os vestígios humanos deixados pelos nossos antepassados.

(KI-ZERBO, A História da África Negra, volume I, p. 17)

Desde que o homem existe, a história existe. (...) A escrita fixa a memória da história, mas quem cria a história é a vida social.

(Dirceu Lindo. Lições de Etnologia Geral, p. 56)

\section{Sobre os conceitos}

A chamada "virada antropológica" na História deu-se nas décadas de 1970 e 1980 com a ampliação de temas de pesquisa ligados à cultura². De fato, ao voltar o olhar para a temática cultural - movimento que já vinha acontecendo na historiografia desde o século XVIII e intensificado com a Escola dos Annales - os historiadores puderam refletir objetos que, até então, estavam mais fortemente vinculados às pesquisas antropológicas e etnológicas. Um aspecto a ser levado em consideração nesse novo momento do século $X X$ são os contextos político-econômicos do "terceiro mundo" e as pesquisas sociais aí desenvolvidas. As lutas de independência em África, contra os regimes totalitários na América Latina e a valorização dos estudos culturais populares impunham novas necessidades à disciplina.

Ou seja, percebia-se que, diferente do embate político oficial, formas culturais subalternas serviam nesses contextos como instrumentos de contestação (no caso da América Latina), valorização e criação de uma identidade local de resistência em contraponto ao colonialismo (no caso de África), etc. Parte dos estudos históricos sobre as culturas passaram a buscar referências teóricas, conceitos e ferramentas metodológicas capazes de extrair um entendimento completo dessas realidades sociais específicas e a se fazer a crítica do tipo de produção existente até o momento. A interdisciplinaridade nas ciências sociais e humanas passou a ser uma aliada para tais estudos.

\footnotetext{
2 Patrimônio intelectual e material - quase sempre heterogêneo, mas às vezes relativamente integrado, outras vezes internamente antagônico, durável em seu conjunto, mas sujeito a contínuas transformações, em ritmo que varia segundo a natureza dos seus elementos e das épocas - constituído por: a) por valores, normas, conceitos, linguagens, símbolos, sinais, modelos de comportamento, técnicas mentais e corporais, com função cognitiva, afetiva, valorativa, expressiva, reguladora, manipuladora; b) pelas objetivações, suportes, veículos materiais ou corporais dos mesmos; c) pelos meios materiais para a produção e a reprodução social do homem, que é produzido e desenvolvido inteiramente pelo trabalho e pela interação social, patrimônio esse geralmente herdado das gerações passadas, inclusive de outras sociedades, e somente em pequena parte produzido originalmente ou modificado pelas gerações vivas - que os membros de uma determinada sociedade compartilham, em variada medida, ou a cujas partes podem seletivamente ter acesso ou dele se apropriar, sob certas condições. DICIONÁRIO DE SOCIOLOGIA. Cultura, p. 174.
} 
Historiadores, educadores e outros começaram a utilizar, por exemplo, as metodologias de pesquisa-ação e pesquisa-participante numa clara afirmação de posições políticas vinculadas à prática de pesquisas diversas.

Minha preocupação é discutir parte da problemática criada nesse amplo contexto de produção. Para aí identificar alguns caminhos de pesquisa aos estudantes-pesquisadores de História. Busca-se refletir aqui, em especial, a relação interdisciplinar da História com a Antropologia e a Etnologia. É necessário para isso apresentar sucintamente o entendimento que se tem dos conceitos e das escolas teóricas utilizados nesse diálogo. Primeiro: o que se entende por História. Segundo: o que se entende por Antropologia e Etnologia. Essa preocupação não é meramente didática. Ela indica a priori a escolha de determinados métodos e também o enfoque dado à pesquisa. Além do mais existem diferentes definições para estes termos ou áreas que se modificaram ao longo do tempo em função de seus "usos e abusos"; mudanças de paradigmas, novas teorias que puseram em cheque as anteriores, tensões políticas no campo da ciência, etc. Faz-se útil, pois, esclarecê-los.

Para o historiador iniciante a definição de sua disciplina, ou do campo de ação de sua área, nem sempre está claro. Muitas vezes, em sala de aula, estudantes e professores ao falarem sobre história têm entre si concepções muito diferentes. Entre os pesquisadores é provável que essa diferença aumente consideravelmente já que aí se colocam as balizas de escolas teóricas, temas e métodos. Dessa forma, a concepção que apresento é aquela que escolho como referência em minha pesquisa e que a meu ver expressa melhor a prática historiográfica, como ofício e como práxis política. Não tenho a pretensão de que essa definição faça eco total com aquela utilizada pelos meus colegas no Curso de História. Entendo a História como a ciência que estuda as transformações na sociedade humana no tempo e no espaço. Sua preocupação é descrever, analisar e interpretar essas transformações numa relação dialética entre passado e presente. É ciência porque se esforça para que o conhecimento produzido tenha "validade em si mesmo" e não seja simplesmente "senso comum" ou meras opiniões eruditas. Para isso, desenvolve um ferramental metodológico que sistematiza os passos para a pesquisa, sem amarrar o processo. A História, já dizia um mestre, é a disciplina que melhor desenvolve consciência crítica. Seu próprio campo de ação e 
reflexão levaria a isso. Estudar história é sofrido porque quanto mais se entende os processos e as transformações, mais se percebe a historicidade da construção da sociedade, da cultura e das concepções que explicam aquilo que seria o "homem", a identidade do humano. Essa reflexão sobre o que é história e suas atribuições leva a diferentes explicações e posicionamentos. Destaco que a história é ao mesmo tempo a ciência, o método e o processo coletivo de construção de conhecimento (práxis) sobre as transformações no tempo e no espaço que leva a uma percepção mais consciente do local social (do lugar) em que se está inserido como indivíduo e como grupo. Há, assim, necessariamente, uma conseqüência política em qualquer produção historiográfica: pode ser transformar e interferir no processo histórico ou a manutenção e a justificação das estruturas dominantes. A maioria dos cientistas concorda que não existe ciência neutra. Afirmo, como outros, que não há pesquisa histórica neutra.

Entendo que, em tais afirmações, há uma série de pressupostos ligados ao desenvolvimento de nossa disciplina no Ocidente. De fato, a História como produção acadêmica é estreitamente vinculada às bases filosóficas e teóricas da visão de mundo do homem ocidental. Ela é etnocêntrica, mais precisamente, eurocêntrica. No entanto, muitos historiadores dos países que foram colonizados reapropriam-se dessa base teórico-metodológica e a utilizaram para a crítica e como aporte de mudança das diferentes realidades nacionais e da dominação colonialista (imperialista). Entra-se, pois, como na epígrafe acima, no "jogo do Ocidente". Vale lembrar que esse jogo é passível de regras: as estruturas sócio-políticas e econômicas que são construídas historicamente podem ser (e são), da mesma forma, desconstruídas.

Outra perspectiva é entender a História como a percepção da mudança no tempo, independente de se ter isso entendido como ciclo ou crescimento. Essa percepção humana não é privilégio do Ocidente. A tradição ocidental não foi a única, nem mesmo a primeira, criadora de formas de registro, e aí deve-se incluir também da oralidade (memória), em função da preservação dos acontecimentos importantes para o grupo social e as futuras gerações. Se retomar-se a história da história vê-se que o grego Heródoto aprendeu com os egípcios, africanos. Os chamados povos ágrafos criavam seus relatos dos fatos 
precedentes. Por exemplo, os griots $^{3}$, contistas oficiais no Reino do Mali, mantinham listas dos seus reis - que podiam contar com centenas de nomes preservados na memória para ser resgatados pelo grupo através desse especialista. O desconhecimento ou a desconsideração desses fatos na produção histórica ocidental diz respeito à visão de que a África estaria presa num continuísmo ou num passado pré-histórico, passando a existir somente a partir da Colonização e do contato como o europeu; dependente do exterior para que transformações internas ocorressem. Como afirma o historiador Elikia M'Bokolo, "longe de ser recheada apenas com as continuidades, este tempo longo do passado africano foi talvez, em primeiro lugar, o das invenções contínuas, sob a forma de uma incessante bricolagem, de laboriosas adaptações ou de rupturas radicais"".

Vê-se assim que a herança eurocêntrica da história como produção acadêmica e práxis social das elites está sofrendo um processo sistemático de desconstrução a partir do surgimento de novas posturas nas pesquisas e da utilização dos novos métodos e fontes. A Antropologia, também nesse sentido, é uma ciência que surgiu no âmbito do colonialismo e teve suas origens entre os séculos XVIII e XIX. De modo geral, a antropologia estuda o homem e a humanidade em todas as suas dimensões. Segue as definições do antropólogo Vagner Gonçalves da Silva:

A Antropologia é o estudo do homem como ser biológico, social e
cultural. Sendo cada uma destas dimensões por si só muito ampla, o
conhecimento antropológico geralmente é organizado em áreas que
indicam uma escolha prévia de certos aspectos a serem privilegiados
como a "Antropologia Física ou Biológica" (aspectos genéticos e
biológicos do homem), "Antropologia Social" (organização social e
política, parentesco, instituições sociais), "Antropologia Cultural"
(sistemas simbólicos, religião, comportamento) e "Arqueologia"
(condições de existência dos grupos humanos desaparecidos). Além
disso, podemos utilizar termos como Antropologia, Etnologia e
Etnografia para distinguir diferentes níveis de análise ou tradições
acadêmicas. Para o antropólogo Claude Lévi-Strauss (1970:377) a
etnografia corresponde "aos primeiros estágios da pesquisa:
observação e descrição; trabalho de campo". A etnologia, com relação
à etnografia, seria "um primeiro passo em direção à síntese" e a
antropologia "uma segunda e última etapa da śntese, tomando por
base as conclusões da etnografia e da etnologia". Qualquer que seja a
definição adotada é possível entender a antropologia como uma forma

\footnotetext{
3 Uma produção histórica maior sobre os griots tem surgido nos últimos anos. Leva-se em conta neles os debates sobre a oralidade com auxílio inclusive da área de lingüística. Os historiadores africanos e africanistas têm se debruçado sobre os diferentes registros feitos em África, numa busca sistemática por desconstruir os discursos racistas sobre o continente africano.

${ }^{4}$ Elikia M'BOKOLO. África Negra: História e Civilizações. Tomo I, p. 12.
} 
de conhecimento sobre a diversidade cultural, isto é, a busca de respostas para entendermos o que somos a partir do espelho fornecido pelo "Outro"; uma maneira de se situar na fronteira de vários mundos sociais e culturais, abrindo janelas entre eles, através das quais podemos alargar nossas possibilidades de sentir, agir e refletir sobre o que, afinal de contas, nos torna seres singulares, humanos. ${ }^{5}$

A objetividade das definições de Silva joga luz na discussão. Percebe-se em sua definição já uma tentativa de superação do ponto de vista etnocêntrico na questão da alteridade. A princípio, "o Outro" para o ocidental era o selvagem ou o bárbaro. O evolucionismo do século XIX na antropologia influenciou a primeira geração de estudos sobre a cultura negra no Brasil com Nina Rodrigues. Na seqüência, o culturalismo norte-americano influenciou os trabalhos de Arthur Ramos, Gilberto Freyre e outros etnólogos. Estes fizeram nos anos 1930 a 1940 os estudos étnicos culturais no país com preocupações claras sobre a formação e afirmação da identidade brasileira. No Brasil, o "Outro" (africano, indígena) transformar-se-ia em "Nós", via a mestiçagem e o discurso da democracia racial, sem de fato, haver uma integração no plano social e econômico da maior parte da população.

Os historiadores, no que diz respeito à produção acadêmica sobre cultura negra no Brasil, só irão contribuir a partir de meados das décadas de 1970 e mais fortemente nas décadas de 1980 e 1990. Dessa forma, os dados etnográficos colhidos desde o início do século começaram a ser trabalhados numa perspectiva histórica. As contribuições de Clóvis Moura, Joel Rufino dos Santos, Wilson do Nascimento Barbosa são essenciais para isso. Como também os trabalhos sobre o período colonial de Laura de Mello e Souza, Mary Del Priori e outros que a partir da década de 1990 aumentaram o interesse sobre essa temática.

É certo que a relação entre a história e antropologia foi discutida desde Franz Boas sobre a utilidade do método histórico para a antropologia em produção do final do XIX e, no século XX, com os trabalhos de Claude LéviStrauss, Evans-Pritchard e Marshall Sahlins. Abaixo tem-se um quadro de referência sobre as diferentes escolas antropológicas que auxilia na visualização do processo de desenvolvimento das discussões desta área.

\footnotetext{
${ }^{5}$ Vagner Gonçalves da SILVA. Antropologia. Disponivel em http://www.fflch.usp.br/da/vagner/antropo.html. Data de acesso: 15/11/2009. Grifo meu.
} 
Tabela: Escolas Interpretativas na Antropologia Cultural ${ }^{6}$

\begin{tabular}{|c|c|c|c|}
\hline Escola / Período & Características & Temas e Conceitos & $\begin{array}{l}\text { Representantes e obras de } \\
\text { referência }\end{array}$ \\
\hline $\begin{array}{l}\text { Formação de uma } \\
\text { literatura } \\
\text { "etnográfica" sobre a } \\
\text { diversidade cultural } \\
\text { Séculos XVI-XIX }\end{array}$ & $\begin{array}{l}\text { Relatos de viagens } \\
\text { (Cartas, Diários, } \\
\text { Relatórios etc.) feitos } \\
\text { por missionários, } \\
\text { viajantes, } \\
\text { comerciantes, } \\
\text { exploradores, } \\
\text { militares, } \\
\text { administradores } \\
\text { coloniais etc. }\end{array}$ & $\begin{array}{l}\text { Descrições das terras } \\
\text { (Fauna, Flora, } \\
\text { Topografia) e dos } \\
\text { povos "descobertos" } \\
\text { (Hábitos e Crenças). } \\
\text { Primeiros relatos } \\
\text { sobre a Alteridade. }\end{array}$ & $\begin{array}{l}\text { Pero Vaz Caminha ("Carta } \\
\text { do Descobrimento do Brasil" } \\
\text { - séc. XVI). Hans Staden } \\
\text { ("Duas Viagens ao Brasil" - } \\
\text { séc. XVI). Jean de Léry } \\
\text { ("Viagem a Terra do Brasil" - } \\
\text { séc. XVI). Jean Baptiste } \\
\text { Debret ("Viagem Pitoresca e } \\
\text { Histórica ao Brasil" - séc. } \\
\text { XIX). }\end{array}$ \\
\hline $\begin{array}{l}\text { Evolucionismo Social } \\
\text { Século XIX. }\end{array}$ & $\begin{array}{l}\text { Sistematização do } \\
\text { conhecimento } \\
\text { acumulado sobre os } \\
\text { "povos primitivos". } \\
\text { Predomínio do } \\
\text { trabalho de gabinete. }\end{array}$ & $\begin{array}{l}\text { Unidade psíquica do } \\
\text { homem. Evolução } \\
\text { das sociedades das } \\
\text { mais "primitivas" para } \\
\text { as mais "civilizadas". } \\
\text { Busca das origens } \\
\text { (Perspectiva } \\
\text { diacrônica). Estudos } \\
\text { de Parentesco } \\
\text { /Religião/Organização } \\
\text { Social. Substituição } \\
\text { conceito de raça pelo } \\
\text { de cultura. }\end{array}$ & $\begin{array}{l}\text { Maine ("Ancient Law" - } \\
\text { 1861). Herbert Spencer } \\
\text { ("Princípios de Biologia" - } \\
\text { 1864). E. Tylor ("A Cultura } \\
\text { Primitiva" - 1871). L. Morgan } \\
\text { ("A Sociedade Antiga" - } \\
\text { 1877). James Frazer ("O } \\
\text { Ramo de Ouro" - 1890). }\end{array}$ \\
\hline $\begin{array}{l}\text { Escola Sociológica } \\
\text { Francesa } \\
\text { Século XIX }\end{array}$ & $\begin{array}{lr}\text { Definição } r & \text { dos } \\
\text { fenômenos sociais } \\
\text { como objetos de } \\
\text { investigação sócio- } \\
\text { antropológica. } \\
\text { Definição das regras } \\
\text { do } \quad \text { método } \\
\text { sociológico. }\end{array}$ & $\begin{array}{l}\text { Representações } \\
\text { coletivas. } \\
\text { Solidariedade } \\
\text { orgânica e mecânica. } \\
\text { Formas primitivas de } \\
\text { classificação } \\
\text { (totemismo) e teoria } \\
\text { do conhecimento. } \\
\text { Busca pelo Fato } \\
\text { Social Total (biológico } \\
+ \text { psicológico + } \\
\text { sociológico). A troca e } \\
\text { a reciprocidade como } \\
\text { fundamento da vida } \\
\text { social (dar, receber, } \\
\text { retribuir). }\end{array}$ & $\begin{array}{l}\text { Émile Durkheim: "Regras do } \\
\text { método sociológico"- 1895; } \\
\text { "Algumas formas primitivas } \\
\text { de classificação" - c/ Marcel } \\
\text { Mauss - 1901; "As formas } \\
\text { elementares da vida } \\
\text { religiosa" - 1912. Marcel } \\
\text { Mauss: "Esboço de uma } \\
\text { teoria geral da magia" - c/ } \\
\text { Henri Hubert - 1902-1903; } \\
\text { "Ensaio sobre a dádiva" - } \\
\text { 1923-1924; "Uma categoria } \\
\text { do espírito humano: a noção } \\
\text { de pessoa, a noção de eu"-- } \\
\text { 1938). }\end{array}$ \\
\hline $\begin{array}{l}\text { Funcionalismo } \\
\text { Século XX - anos } 20\end{array}$ & $\begin{array}{l}\text { Modelo de etnografia } \\
\text { clássica } \\
\text { (Monografia). Ênfase } \\
\text { no trabalho de campo } \\
\text { (Observação } \\
\text { participante). } \\
\text { Sistematização do } \\
\text { conhecimento sobre } \\
\text { acumulado solu } \\
\text { uma cultura. }\end{array}$ & $\begin{array}{l}\text { Cultura } r \text { como } \\
\text { totalidade. Interesse } \\
\text { pelas Instituições e } \\
\text { suas Funções para a } \\
\text { manutenção da } \\
\text { totalidade cultural. } \\
\text { Énfase na Sincronia x } \\
\text { Diacronia. }\end{array}$ & $\begin{array}{l}\text { Bronislaw } \\
\text { ("Argonautas do Pacífico } \\
\text { Ocidental" -1922). Radcliffe } \\
\text { Brown ("Estrutura e função } \\
\text { na sociedade primitiva" - } \\
\text { 1952-; e "Sistemas Políticos } \\
\text { Africanos de Parentesco e } \\
\text { Casamento", org. c/ Daryll } \\
\text { Forde - 1950). Evans- } \\
\text { Pritchard ("Bruxaria, } \\
\text { oráculos e magia entre os } \\
\text { Azande"- - 1937; "Os Nuer" - } \\
\text { 1940). Raymond Firth ("Nós, }\end{array}$ \\
\hline
\end{tabular}

\footnotetext{
${ }^{6}$ Tabela baseada em informações de Vagner Gonçalves da SILVA, op.cit.
} 


\begin{tabular}{|c|c|c|c|}
\hline & & & $\begin{array}{l}\text { os Tikopia" - 1936; } \\
\text { "Elementos de organização } \\
\text { social - 1951). Max Glukman } \\
\text { ("Ordem e rebelião na África } \\
\text { tribal"- 1963). Victor Turner } \\
\text { ("Ruptura e continuidade em } \\
\text { uma sociedade africana"-- } \\
\text { 1957; "O processo ritual"- } \\
\text { 1969). Edmund Leach - } \\
\text { ("Sistemas políticos da Alta } \\
\text { Birmânia" - 1954). }\end{array}$ \\
\hline $\begin{array}{l}\text { Culturalismo Norte- } \\
\text { Americano } \\
\text { Séc. XX - anos } 30\end{array}$ & $\begin{array}{l}\text { Método comparativo. } \\
\text { Busca de leis no } \\
\text { desenvolvimento das } \\
\text { culturas. Relação } \\
\text { entre cultura e } \\
\text { personalidade. }\end{array}$ & $\begin{array}{l}\text { Ênfase na construção } \\
\text { e identificação de } \\
\text { padrões culturais } \\
\text { ("patterns of culture") } \\
\text { ou estilos de cultura } \\
\text { ("ethos"). }\end{array}$ & $\begin{array}{l}\text { Franz Boas ("Os objetivos } \\
\text { da etnologia" - 1888; "Raça, } \\
\text { Língua e Cultura" - 1940). } \\
\text { Margaret Mead ("Sexo e } \\
\text { temperamento em três } \\
\text { sociedades primitivas" - } \\
\text { 1935). Ruth Benedict } \\
\text { ("Padrões de cultura" - 1934; } \\
\text { "O Crisântemo e a espada"- } \\
\text { 1946). }\end{array}$ \\
\hline $\begin{array}{l}\text { Estruturalismo } \\
\text { Século XX - anos } 40\end{array}$ & $\begin{array}{lr}\text { Busca das regras } \\
\text { estruturantes das } \\
\text { culturas presentes na } \\
\text { mente humana. } \\
\text { Teoriarara do } \\
\text { parentesco/Lógica do } \\
\text { mito/Classificação } \\
\text { primitiva. Distinção } \\
\text { Natureza x Cultura. }\end{array}$ & $\begin{array}{lr}\text { Princípios } & \text { de } \\
\text { organização da } \\
\text { mente humana: pares } \\
\text { de oposição e } \\
\text { códigos binários. } \\
\text { Reciprocidade. }\end{array}$ & 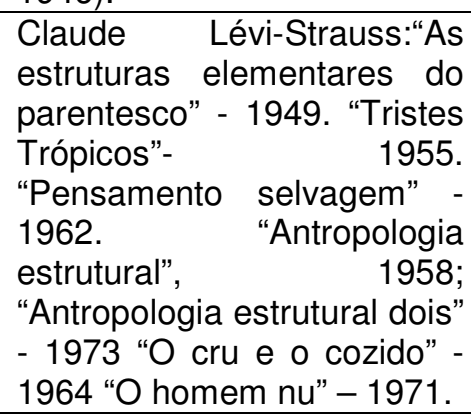 \\
\hline $\begin{array}{l}\text { Antropologia } \\
\text { Interpretativa } \\
\text { Século XX - anos } 60 .\end{array}$ & $\begin{array}{lr}\text { Cultura } & \text { como } \\
\text { hierarquia de } & \text { significados Busca da } \\
\text { "descrição densa". } \\
\text { Interpretação x Leis. } \\
\text { Inspiração } \\
\text { Hermenêutica. }\end{array}$ & $\begin{array}{l}\text { Interpretação } \\
\text { antropológica: Leitura } \\
\text { da leitura que os } \\
\text { "nativos" fazem de } \\
\text { sua própria cultura. }\end{array}$ & $\begin{array}{l}\text { Clifford Geertz: "A } \\
\text { interpretação das culturas" - } \\
\text { 1973. "Saber local" - 1983. }\end{array}$ \\
\hline $\begin{array}{l}\text { Antropologia Pós- } \\
\text { Moderna ou Crítica } \\
\text { Século XX - nos } 80\end{array}$ & 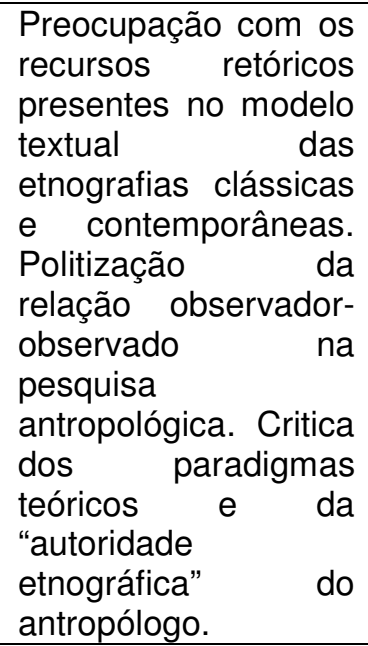 & 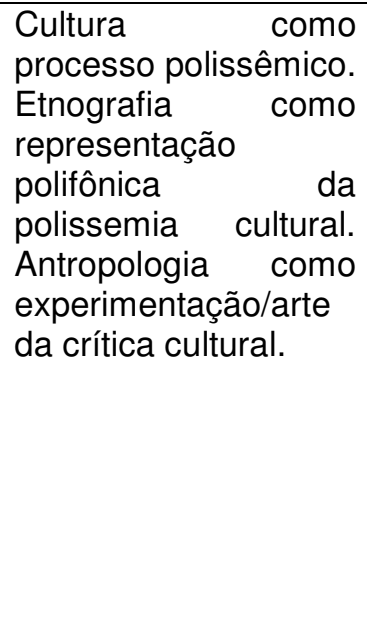 & $\begin{array}{l}\text { James Clifford e Georges } \\
\text { Marcus ("Writing culture - } \\
\text { The poetics and politics of } \\
\text { ethnography" - 1986). } \\
\text { George Marcus e Michel } \\
\text { Fischer ("Anthropoly as } \\
\text { cultural critique" - 1986). } \\
\text { Richard Price ("First time"- } \\
\text { 1983). Michel Taussig } \\
\text { ("Xamanismo, colonialismo e } \\
\text { o homem selvagem"- 1987). } \\
\text { James Clifford ("The } \\
\text { predicament of culture" - } \\
\text { 1988). }\end{array}$ \\
\hline
\end{tabular}

As escolas interpretativas apresentadas foram incorporadas em diferentes produções historiográficas. O movimento contrário também surgiu. É certo que 
as reflexões dos antropólogos e etnólogos sobre os usos da História em suas áreas contribuiu muito para a crítica daqueles pressupostos do colonialismo. Observe-se o comentário de Dirceu Lindoso sobre isso:

\begin{abstract}
O etnólogo, ao contrário do historiador, deve desenvolver em sua aprendizagem de campo uma percepção antropológica da expressão povo sem história. Saber que a expressão expressa um simulacro, e que esse simulacro se produz em função da maneira como a história se apresenta na estrutura social das sociedades primitivas que nos são contemporâneas. Não é que a história não exista. É que a história existe. De uma maneira sutil, e age na estrutura social das sociedades primitivas. Isso é o que chama de agir de certa maneira. Todos os povos têm história, mesmo os pré-históricos, porque são os nossos antepassados. E ter um antepassado é ter uma história. E se ela é perceptível ou não, isso é outra história. Mas a percepção antropológica da história deve ser criada, só que não pode ser criada ao modo da escrita, criada pelas técnicas mnemotécnicas dos alfabetos e ideogramas. Desde que o homem existe, a história existe; só que para ser criada a história escrita, as sociedades que tiveram que se dividir em classes, com cujo tempo disponível adveio a escrita. A escrita fixa a memória da história, mas quem cria a história é a vida social. $^{7}$
\end{abstract}

Também é certo que uma produção histórica voltada para a cultura no século XX explorou junto ao desenvolvimento das teorias antropológicas possibilidades de análise com novos temas. A História Cultural não seria, nas palavras de Peter Burke, "uma descoberta ou invenção nova". Ele divide-a em quatro fases: (a) a fase "clássica" entre 1800 e 1950 - Jacob Burkhardt ( $A$ cultura do Renascimento na Itália, 1869) e Johan Huizinga ( $O$ outono da Idade Média, 1919); (b) da "história da arte", que começou na década de 1930 (Aby Warburg; Fritz Saxl; Edgar Wind e Erwin Panofsky); (c) a descoberta da "história da cultura popular", na década de 1960 (Eric Hobsbawn; Edward Thompson; Jacques Le Goff); e (d) a "nova história cultural", final da década de 1980 (Lynn Hunt; Natalie Davis, Jacques Le Goff e outros com influências de Mikhail Bakhtin, Norbert Elias, Michel Foucault e Pierre Bourdieu). ${ }^{8}$ De acordo com Burke, a respeito da "nova história cultural" (NHC) "a realização coletiva das duas ou três últimas décadas é considerável, e o movimento torna-se mais impressionante quanto visto como um todo. Se ocorreram poucas inovações de método, no sentido estrito do termo, muitos novos temas foram descobertos e

\footnotetext{
7 Dirceu LINDOSO. Lições de Etnologia, p. 56. O autor afirma nesse texto como é importante entender essa explicação para a etnologia, diferente da discussão historiográfica. A referência a povos sem história vem de Hegel em sua obra a Filosofia da História. A negação da possibilidade dos povos africanos de ter história, por exemplo, é a máxima expressão do eurocentrismo e está de acordo com a mentalidade colonialista do século XIX.

8 Peter BURKE. O que é História Cultural?, pp. 15-96.
} 
explorados com a ajuda de novos conceitos". Mesmo com certa continuidade entre os períodos teria havido, segundo Burke, "um deslocamento ou uma virada coletiva na teoria e na prática da história cultural", com uma "mudança de ênfase mais que a ascensão de uma coisa nova". No entanto, isto não teria se dado sem contestações. Lembra Burke que a teoria subjacente à nova história cultural foi questionada por historiadores como Edward Thompson ("A pobreza da teoria", 1978). Ainda segundo Burke, "o tradicional conceito antropológico de cultura como um mundo concreto e delimitado de crenças e práticas foi criticado com base na afirmação de que as culturas são locais de conflitos, e integradas de maneira frouxa". Outra controversa seria a respeito dos conceitos de "construção cultural da realidade" e "representação". 9

Percebe-se que a ampliação das temáticas e o contato com outras áreas das ciências sociais levaram os historiadores da cultura a refletir as implicações de suas escolhas teóricas em novos níveis, às vezes, criando-se novas dificuldades. Quero exemplificar parte delas a partir dos exemplos específicos de minha área de pesquisa.

\section{Sobre os objetos de pesquisa}

Dentre os temas da cultura que a História passa a lidar têm-se aqueles das religiões ou religiosidades. A área de História das Religiões é uma das que mais produziram nas últimas décadas e que está também particularmente utilizando elementos advindos da antropologia e outras ciências sociais e humanas. O objeto de pesquisa "religiões" cresceu junto com a História Cultural mas logo abriu um campo próprio com perspectivas teórico-metodológicas bem diversas. ${ }^{10}$ Fica explícito em um primeiro momento a escolha do termo religiões em detrimento da religião no singular. Uma primeira ruptura teria sido aquela tentativa nas ciências sociais em desteologizar os estudos de religião e levá-los para o campo das possibilidades de análises científicas. Nesse aspecto

\footnotetext{
9 Peter BURKE, op. cit., pp. 97-98.

10 Massenzio apresenta três vertentes teóricas na história das religiões, tal como entendidas pela Escola Italiana: (a) a vertente sistemática: Müller, Tylor e Durkheim; (b) a vertente fenomenológica (essencialista): Otto, Van der Leuw e Eliade, e; (c) a vertente italiana: Petazzoni, De Martino, Lanternari e outros. (MASSENZIO, M. A História das Religiões na cultura moderna, pp. 11-27) Há de se considerar também a História Religiosa dos franceses. De fato, a produção de Eliade está muito próxima da produção das Ciências da Religião, de base teológica. Apesar disso, a tentativa de criar interpretações gerais para o fenômeno religioso humano, levou essa escola também a utilizar amplamente os métodos da etnografia e etnologia, no levantamento de dados específicos e síntese sobre diferentes religiões no mundo.
} 
importou em especial a "antropologia religiosa", área de confluência entre a história das religiões e a antropologia cultural. Em outro nível também os trabalhos de E. Durkheim, L. Feuerbach, Karl Marx, Max Weber e outros. A abertura para o conhecimento do "Outro", a crítica ao etnocentrismo (eurocentrismo) e os estudos das relações entre Ocidente e o Terceiro expressos nos movimentos religioso-sociais (no "Terceiro Mundo" em especial) foram importantes para que os historiadores das religiões e os etnólogos colocassem alguns problemas epistemológicos. Afirma Massenzio:

$\mathrm{O}$ fato de assumir como objetivo o conhecimento do culturalmente diverso criou, e continua a criar problemas epistemológicos muito complexos, para os quais os estudiosos deram soluções divergentes no curso do tempo. Por exemplo, com o auxílio de quais critérios, de quais categorias interpretativas pode-se adequadamente estudar civilizações que não participam da tradição ocidental? Como reflexo, a questão geral tem a ver com o papel do Ocidente dentro de um cenário cultural enormemente dilatado. Quanto à religião, coloca-se, nesse âmbito, um quesito fundamental: é suficiente, é apropriada a bagagem conceitual forjada de maneira prevalente em função do cristianismo para o estudo de outros universos religiosos? Ou seria necessário construir outros quadros de referência? Levar em conta tais perguntas, repensá-las à luz da história do pensamento antropológico e históricoreligioso contemporâneo significa enfrentar o problema da religião de modo novo, consoante ao tempo em que estamos vivendo. ${ }^{11}$

Um exemplo clássico desse debate é a "noção ocidental de magia". Segundo Massenzio tal noção é o produto de "longuíssimo processo cultural" que caracterizou de maneiras nem sempre uniformes, as fazes históricas do Ocidente. Assim, a "polêmica magia x religião" e a conseqüente desvalorização da magia representam algumas dessas etapas mais importantes. Fica claro para o autor que:

\begin{abstract}
Do que foi dito (...) evidencia-se que existe uma ligação inextrincável, de natureza dialética, entre o plano da criação cultural (que compreende tanto as elaborações conceituais quanto os juízos de valor) e um determinado âmbito histórico. Como conseqüência, qualquer produto cultural, qualquer noção, não pode ser alienado do contexto que contribuiu de maneira decisiva para conferir a eles uma fisionomia bem determinada. Concretamente, analisar as "outras" culturas, que não foram tocadas pela polêmica antimágica típica do Ocidente por meio do conceito de magia que é fruto maduro dessa polêmica, representa uma incongruência epistemológica, a qual não pode produzir ganhos no plano do processo cognitivo. ${ }^{12}$
\end{abstract}

Nesse sentido, os estudos sobre as religiões negras no Brasil ou afroindígenas sofreram dessa transposição de conceitos. Às vezes, refletindo

\footnotetext{
${ }^{11}$ Marcello MASSENZIO. A História das Religiões na cultura moderna, p. 38.

${ }^{12}$ Marcello MASSENZIO. Op. cit., pp. 44-45.
} 
conflitos de âmbito social: étnicos e/ou político-religiosos. O histórico ataque às religiões de matriz africana e indígena foi posto em ternos de conflito entre magia (falsidade) e religião (verdade) em alguns momentos. Sendo categorizada com menos valor as religiões ditas "mágicas". De fato, o próprio uso da categoria "religião" gera polêmica, pois se costuma nos meios cristãos, católicos e protestantes, denominá-las "seitas" adjetivadas de "demoníacas". Vê-se que mesmo considerando tal polêmica como conflitos ou concorrência entre os campos religiosos, ou racismos permanentes na sociedade brasileira, há de fato uma utilização, nas pesquisas sobre religião no país, dessas categorias sem uma reflexão sobre a construção histórica desses conceitos. 0 mesmo pode ser dito do termo "mito", que na civilização ocidental "sofre o efeito do condicionamento exercido a partir da filosofia grega", na oposição entre logos (o discurso racionalmente estruturado) e mythos (o discurso que desconhece a estrutura lógica). ${ }^{13}$ Assim, nenhum conhecimento que esteja fora do âmbito do simbolicamente dominante na sociedade é considerado em sua explicação interna e válido. Transformaram-se assim em folclore as mitologias afro-brasileiras em oposição aos mitos bíblicos tratados como sabedoria ou "verdade em si mesmo". O esforço por desteologizar os estudos de religião soma-se ao esforço por descristianizar seus conceitos e referências. Eis aí o desafio posto no questionamento acima de Massenzio.

Tem-se que essa discussão na história das religiões tende a incorporar as lutas ideológicas das sociedades em que tais estudos se fazem. Nas sociedades latino-americanas, com as mudanças no âmbito da pertença religiosa da população, fica claro que não se pode mais lidar com categorias fixas. A pertença religiosa dupla ou às vezes múltipla surgiu na coleta de dados das pesquisas de sociologia da religião e começou a ser aceitas pelos pesquisadores como uma realidade da prática religiosa do povo brasileiro. Muitas pessoas freqüentam diferentes religiões ao longo da vida, sentindo-se vinculadas a cada uma delas, sem conflitos. Outro ponto, indicado no último

\footnotetext{
13 Marcello MASSENZIO. Op. cit., p. 47. A vertente fenomenológica na história das religiões procurou criar uma categoria explicativa para mito como estrutura arquetípica contraposta, por exemplo, à realidade. A partir da concepção jungiana, Eliade, Campbell e outros afirmaram que a humanidade teria desenvolvido ao longo do tempo determinadas categorias de mitos universais, com diferentes interpretações culturais que espelham um inconsciente coletivo humano. Tais estudiosos ultrapassam a perspectiva ocidental para mito, ao dar a este um valor de sabedoria humana profunda, mas tendem a transcender seus sentidos das realidades históricas que os construíram. O Sagrado e o Profano em Eliade segue nessa linha distinguindo como dois níveis opostos, mas que dialogam.
} 
senso de 2000 é o aumento dos fiéis nas religiões cristãs neo-pentecostais, e o aumento daqueles que se identificam como sem-religião. Por outro lado, a diminuição daqueles que se identificam como membros das religiões afrobrasileiras e, nas últimas décadas, a perda de fiéis pela Igreja Católica. Essas informações ultrapassam o âmbito cultural e trazem questões para a história das religiões no modo como elas se desenvolveram no Brasil, como também as influências das mudanças na vida sócio-econômica do país que interferiram nessas transformações. Ao se olhar historicamente para as religiões no Brasil ver-se-á uma clara oposição entre o modo como as religiões populares (afroindígenas; catolicismo popular etc) se desenvolveram, interpenetraram-se e conviveram ao longo do tempo - e o modo como as hierarquias religiosas, especialmente, católicas e agora também evangélicas - relacionaram-se com o Estado e os governos na manutenção das estruturas dominantes. Falta ainda uma tentativa de teoria explicativa histórica geral para estes fatos.

\section{Sobre as o uso das fontes antropológicas na escrita da História}

Voltando o olhar para a relação entre história e antropologia, penso ser interessante exemplificar problematizando com a minha pesquisa de doutorado os modos como essa relação fica mais evidente no cotidiano do pesquisador.

(A) a primeira percepção que o historiador tem ao iniciar sua pesquisa sobre as religiões afro-brasileiras é a falta de uma bibliografia historiográfica sobre o tema. É possível encontrar em alguns trabalhos históricos do período colonial até o segundo Império informações sobre os cultos afro-indígenas. No entanto, tais temas surgem de modo indireto, não sendo dedicado a eles um tratamento mais aprofundado. De fato, é recente uma produção que procurará historiar as religiões afro-indígenas. Notem: os trabalhos existentes hoje, com algum tratamento histórico, são feitos por antropólogos e etnólogos. A bibliografia que o historiador encontra, iniciando com os chamados "clássicos", a partir de Nina Rodrigues no final do século XIX, é antropológica e etnológica. A sociologia também terá a partir dos anos 1940 uma produção mais sistemática sobre o tema. O pesquisador tem como primeira percepção, desse modo, que a história trabalha tão somente com a escravidão e escravismo, enquanto os temas culturais seriam prerrogativa das ciências sociais outras. 
(B) Com a carga de leituras antropológicas e sociológicas o historiador irá então a campo. Ou seja, começará a sua busca pelos dados, as fontes. Outro problema. Primeiro ele deverá se adequar aos métodos de coleta de dados. A visita aos terreiros de Candomblé e Tendas de Umbandas, por exemplo, podem ser feitas de diferentes formas. No entanto, a literatura existente coloca-Ihe algumas tarefas. Por exemplo, ao ler Roger Bastide fica-se com a impressão que o melhor caminho é fazer um "estudo de caso", uma monografia sobre "um" terreiro. Quanto mais específico for o estudo, melhor esse seria. Há uma visão sincrônica intrínseca nesse método. Para isso, a pesquisa-participante e a construção dos diários de campo ainda seriam aqueles métodos privilegiados. $O$ pesquisador deveria freqüentar a religião como membro para melhor entender seus pressupostos, conhecer seus segredos, etc. O historiador estranha muito esse método. A opção para este seria utilizar uma observação sistemática dos ritos e cultos e fazer entrevistas com questionário aberto. Outro caminho seria buscar as fontes tradicionais do historiador nos jornais (sessão policial), nos cartórios, nos autos-crimes. Sabese que as religiões afro-brasileiras foram (e são) tratadas ao longo do tempo como casos de polícia, são esses os registros, infelizmente, às vezes, os únicos que se têm e podem ser utilizados com mais facilidade pelo historiador. Outras fontes interessantes são os Códigos de Posturas municipais. Neles encontram-se explicitações das proibições de práticas sociais ligadas às religiões afro-brasileiras ou à segregação do espaço público utilizado por elas. Os diferentes métodos de história oral são para o historiador outro caminho. A possibilidade de criação das fontes orais e seu tratamento têm aumentado a quantidade de informações que se tem sobre a cultura negra e indígena no país.

(C) Penso que não se deve criar uma oposição total entre as fontes etnográficas e as históricas, de fato, ambas são essenciais e complementamse na pesquisa. O importante é que a História possa aumentar a sua contribuição na produção desse conhecimento. Ainda nos encontramos, podese afirmar, no momento da criação de fontes de referência para tais estudos em nossa área. Recordo-me que em um curso fui interrogada por uma aluna do porque, ao nos referirmos às religiões afro-brasileiras, o fazermos ainda em termos tão introdutórios. Respondi-lhe porque, de fato, é ainda a etapa que nos 
encontramos: a descrição. Esta etapa já realizada pela etnografia, analisada pela etnologia e interpretada pela antropologia ainda carece de um tratamento historiográfico sistematizado. Os antropólogos ao recorrerem à História como auxiliar em suas interpretações levou-nos à percepção do quanto nossa disciplina está fora desse debate. Não se pode esquecer que o aumento considerável das produções sobre cultura negra no Brasil e, inclui-se também História da África, são resultados das Leis nacionais e estaduais que tornaram obrigatório o ensino dessas áreas. É imprescindível, a meu ver, que os historiadores que trabalhem com as religiões afro-brasileiras e indígenas sejam capazes de criar além das referências e dos catálogos de fontes, também possam apresentar interpretações do desenvolvimento desses cultos ao longo do tempo, percebendo suas transformações, seus conflitos e as soluções criadas pelos seus membros. Isso se torna mais importante ao se entender o quanto o racismo como ideologia dominante na sociedade brasileira interferiu no modo como tais religiões se organizaram. Os historiadores devem ser capazes de lidar com essa problemática no intuito de construir uma teoria histórica anti-racista no país.

\section{Considerações finais}

Como visto as relações teórico-metodológicas entre história e antropologia é parte de uma tradição de debates bastante profícua e longa de fins do século XIX ao XX. Cada uma delas procurou aprender com a outra os enfoques necessários para um entendimento mais amplo e aprofundado das temáticas culturais. Fica evidente, se observar-se o quadro das escolas interpretativas, acima exposto, que divergências em torno de Diacronia e Sincronia, parecem ser as maiores entre História e Antropologia. Ou melhor, entre as ciências sociais e a histórica. Veja-se abaixo uma tentativa de sistematização dessas diferenças:

\begin{tabular}{|l|l|}
\hline SEMELHANÇA & DIFERENÇA \\
\hline Analogia & Especificidade \\
\hline Combinação & Típico \\
\hline Continuidade & Único \\
\hline Tipologia & Não-repetível; individual; \\
\hline Ciências Humanas & História \\
\hline Sincronia & Diacronia \\
\hline Estático & Dinâmico; estrutura, rede, valor posicional. \\
\hline
\end{tabular}

Fonte: Sara Albieri. Curso Teoria da História, Dept. História, USP, 03/07/2008. 
Essas distinções têm um caráter de esclarecimento no sentido do método utilizado para a construção de interpretações sobre os objetos de estudo. Para o historiador os estudos de caso das religiões afro-brasileiras, por exemplo, devem ser constantemente refletidos à luz das transformações históricas do período estudado. Ou seja, não se deve parar na etapa da coleta de dados e análise interna deles, mas criar explicações históricas sobre tais elementos, com o intuito de compreender no tempo e no espaço suas mudanças. A interdisciplinaridade deve nesse caso servir de apoio. Como diria Max Weber cada área das ciências sociais é uma diferente porta que leva a uma mesma sala.

Por outro lado, a crítica ao eurocentrismo presente nas bases dessas ciências precisa também ser levada em consideração. Mantendo as velhas perguntas que os historiadores fazem às suas fontes: Quem a criou? Com que intenção? Para quem? E, no contato com a observação sistemática ou na oralidade, perceber como aquele indivíduo e/ou aquele grupo interpretam suas práticas, vivem seu cotidiano, transmitem seus conhecimentos, etc. É no caminho do geral para o particular e do particular para o geral, na relação entre a teoria e a empiria e no esforço de criar explicações interpretativas que os historiadores poderão contribuir para o entendimento e transformação das realidades sociais. Nesse caso, específico contribuirá na luta anti-racista no país.

\section{Referências bibliográficas:}

1. ABBAgnANO, Nicola. Diccionario de Filosofia. México: Fondo de Cultura Económico, 2004.

2. GALLINO, Luciano (org.). Dicionário de Sociologia. São Paulo: Editora Paulus, 2005.

3. BURKE, Peter. História e Teoria Social. São Paulo: Editora UNESP, 2002.

4. BURKE, Peter. O que é História Cultural? Rio de Janeiro: Jorge Zahar Ed., 2008.

5. GEERTZ, Clifford. A Interpretação das Culturas. São Paulo: LTC, 1989.

6. LINDOSO, Dirceu. Lições de Etnologia Geral: Introdução ao estudo dos seus princípios; seguido de Dois Estudos de Etnologia Brasileira. Maceió: Edufal, 2008.

7. M’BOKOLO, Elikia. África Negra: História e Civilizações. Tomo I (até o século XVIII). Salvador: Casa das Áfricas, EDUFBA, 2009.

8. MASSENZIO, Marcello. A História das Religiões na cultura moderna. São Paulo: Hedra, 2005. 
9. SCHWARCZ, Lilia K. Moritz. História e Etnologia. Lévi-Strauss e os embates em região de fronteira. Revista de Antropologia vol.42 n.12, São Paulo, 1999.

10.SCHWARCZ, Lilia K. Moritz. Questões de Fronteira: sobre a antropologia da história. Novos estudos - CEBRAP no. 72, São Paulo, July 2005. 